\title{
Popular Science?
}

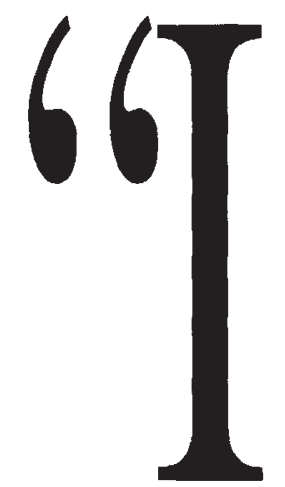

n Germany, teachers especially are prone to join specific trends, being against biotechnology, against nuclear energy, against robots, against genetic engineering in particular, against big science as such, while on the other hand overemphasizing environmental issues without sufficient reflection and differentiation."

"Media leaders in Russia now refuse to publish articles on scientific achievements. They prefer to fill their readers and viewers with pseudo-erotic writings and the speculations of sorcerers, astrologers and phoney prophets. The public tends to blame science and scientists for everything that goes wrong."

Those remarks come from two speakers at a conference held in Geneva last December as a centerpiece of the European Week for Scientific Culture. First, Christian Patermann, Assistant Secretary in the Federal Ministry for Research and Technology in Bonn, Germany, reported on the contemporary fashion in his country of attacking science for its alleged ill-consequences. The ensuing ethos has persuaded several bioscience companies to locate new facilities abroad rather than in their home territory, and in one German state (Lower Saxony) has even led to the banning of any reference to genetic engineering in secondary school curricula.

The second comment was from Viola Egykova, Chief of the Science Desk at the Moscow-based newspaper Moskovskaya Pravda, as she described the near-disappearance of popular science from the media since the collapse of the former Soviet Union. Magazines such as Science and Life and Young Naturalist, which formerly enjoyed a combined circulation of 1.5 to 2 million copies, now sell about a tenth of that number. Of more than 1000 journalists working for the ITAR-TASS News Agency, only ten are now science journalists. Most periodicals no longer cover science at all.

Clearly, all is not well with the public interface of science in at least two parts of Europe. The reasons in each case are doubtless complex and to some degree different. The German situation can be traced inter alia, to the historical legacy of Nazi eugenics, the authoritarian disdain shown by some sections of the scientific establishment toward engagement with journalism and the public, and the rise of the Greens a decade ago. In the former totalitarian countries to the east, on the other hand, we can attribute the replacement of science by pseudo-science to the scientific community's loss of its privileged position, the withdrawal of government support for science magazines and other popularization activities, the opening of the

\author{
BERNARD DIXON
}

floodgates for alternative ideas following the end of censorship--and the nuclear reactor accident at Chernobyl and official responses thereto.

I was taken to task recently by Dorothy Nelkin (Bio/ Technology 11: 1496) for my "Panglossian optimism" as regards a bedrock of public regard for the practical achievements of science-that fund of goodwill that I do believe to be widespread. But, as I tried to emphasize in an earlier commentary (Bio/Technology 11: 1090), public confidence certainly must not be taken for granted, and it cannot be expected to negate the fears and anxieties that people may entertain at one and the same time. As shown by the reports from Germany and Russia, anti-science may thrive, given the right ingredients and encouragement, in virtually any society.

Indeed, public regard for science can always and everywhere change for the worse. That possibility is illustrated by recently published results of the Eurobarometer study carried out a few months ago in the 12 countries of the European Union. Following an identical study conducted two years previously, the new data show that 48 percent of interviewees now believe that biotechnology will "improve our way of life in the next 20 years," as compared with 50 percent in 1991. Fifteen (an increase of 4 ) percent now feel it will make matters worse. Support for specific applications has declined slightly overall, with a particularly pronounced fall in parts of Germany.

When we break down the data, however, there are some telling revelations. In Germany, for example, the lowest level of public support for biotechnology recorded throughout the 12 countries is coupled with the second highest perception of risk. Yet Denmark shows the top rating for risk, coupled with a much greater level of public support (about the European average). Is this linked with the unusual degree of trust recorded by the Danish respondents in public authorities as a source of information on biotechnology? And what of the very striking finding that the greater the knowledge of interviewees throughout Europe concerning biotechnology and genetic engineering, the more they support research in these fields? Is there a causal link between knowledge and attitude?

Eric Marlier, author of the Eurobarometer report, rightly warns us against making easy assumptions of this sort. Nevertheless, the links are rather persuasive. And they certainly help to emphasize that the social contract between science and society is a dynamic one. It can and does alter significantly over time, and is molded in part by initiatives taken by participants and spectators alike. In other words, the social contract is not the unchanging source of doom and difficulty which the pessimists of bioindustry so much enjoy lamenting. 